\title{
"HOW DO YOU FEEL?": EMOTIONS EXHIBITED WHILE \\ PLAYING COMPUTER GAMES AND THEIR RELATIONSHIP \\ TO GAMING BEHAVIORS
}

\author{
Rex P. Bringula \\ University of the East \\ 2219 CM Recto Avenue, Sampaloc, Manila, Philippines 1008 \\ rex_bringula@yahoo.com \\ Kristian Paul M. Lugtu \\ University of the East \\ 2219 CM Recto Avenue, Sampaloc, Manila, Philippines 1008 \\ contact@kristianlugtu.com \\ Ariel D.V. Aviles \\ University of the East \\ 2219 CM Recto Avenue, Sampaloc, Manila, Philippines 1008 \\ co113@yahoo.com
}

\begin{abstract}
This descriptive study utilized a validated questionnaire to determine the emotions exhibited by computer gamers in cyber cafés. We determined that gamers exhibited both positive and negative emotions while playing games. We observed that gamers were inclined to be more anxious about being defeated in a game as gaming became frequent and length of years spent playing games increased. They also had the tendency to become more stressed when length of years spent playing games increased. On the other hand, other gaming behaviors were not significantly related to other emotions. We concluded
\end{abstract}


that not all emotions exhibited by gamers while playing computer games could be attributed to their gaming behaviors. We recommend that other emotions such as anger, frustration, boredom, amusement, etc. be included in future research.

Keywords: Anxiety, Cyber café, Emotions, Gaming, Stress

\section{INTRODUCTION}

The existing literature lacks identification of different emotions exhibited by computer game players while participating in a competitive environment such as an Internet café. Further, most of the literature (e.g., Demirok et al., 2012; Devilly et al., 2012) were focused on a single dimension of emotions expressed while playing computer games. Also, previous investigations (e.g., Hussain and Griffiths, 2009; Bringula et al., 2012; Peols et al., 2013) assumed that gamers had prior emotions (e.g., boredom) that triggered gamers to play computer games. On the other hand, it can be argued that games serve as stimuli inducing gamers to experience different emotions. It is also unknown if players' emotions exhibited while playing computer games are related to their gaming behaviors.

This study attempted to address these research gaps. Toward this goal, it attempted to answer the following questions: 1) What is the profile of the respondents in terms of age, gender, civil status, highest educational attainment, employment, computer access at home, Internet access at home, and family monthly income? 2) What are the gaming behaviors of the respondents in terms of frequency of visits in a week, length of years playing games, games being played, hours spent per visit, and frequency of gaming? 3) What are the emotions exhibited while playing computer games? 4) Is there a significant relationship between emotions exhibited while playing computer games and the gaming behaviors of the respondents?

\section{LITERATURE REVIEW}

Emotion can be defined as "an inferred complex sequence of reactions to a stimulus including cognitive evaluations, subjective changes, autonomic and neural arousal, impulses to action, and behavior designed to have an effect upon the stimulus that initiated the complex sequences" (Plutchik, 1982, p. 551) and as "psychological states that comprise thoughts and feelings, physiological changes, expressive behaviors, and 
inclinations to act" (Manstead, 2007, p. 285). Cannon-Bard theory of emotion (Sullivan, 2009) offered an explanation for how emotions were activated. According to this theory, external stimuli or events could elicit emotion and eventually trigger physiological arousal, or a person could experience emotions simultaneously and independently.

Positive and negative effects are often referred to as the Big Two emotions (Larsen, 2007). The former refers to all high energy emotions that feel good or pleasurable, such as energetic, engagement, joy, happiness, love, and enthusiasm (Larsen, 2007; Tsahuridu, 2009). On the other hand, the latter refers to unpleasant feelings such as anxiety, fear, hate, worry, distress, anger, hostility, and disgust (Larsen, 2007; Tsahuridu, 2009). It has also been argued that positive and negative emotions are independent from one another (Larsen, 2007).

Poels et al. (2013) investigated whether emotions of players during a game could predict length of play and game preferences (i.e. the type and genre of the game). It was revealed that pleasure predicted short-term playing (i.e., immediately after game-play) and game preferences. On the other hand, arousal could affect long-term playing time (i.e., after 3 weeks).

A qualitative analysis on the attitudes, feelings, and experiences of online gamers from 71 participants from 11 countries was conducted by Hussain and Griffiths (2009). They showed that there were six themes related to online gaming. These were: integration of online gaming into day-to-day living, excessive playing and problematic use, addiction, psychosocial impact of online gaming, dissociation and time loss, and lessening of negative mood states and feelings. The study revealed that online games reduced stress, anger, frustration, and loneliness for the players.

On the other hand, the study of Devilly et al. (2012) determined whether or not gamers could change emotions during longer lengths of game play. It was shown that a change in scores for gamers indicated that short gaming durations led to a higher increase in anger ratings than long-term gaming. Their results also disclosed that female gamers showed a larger change in state anger (CSA) than male participants. Also, those who were unexposed to video games with violent content had higher CSA than those who were exposed to these games.

Lastly, Demirok et al. (2012) examined the relationship of time spent playing computer games with violent content and self-reported anger in a population of 400 students in North Cyprus. They revealed that $43 \%$ of the students played computer games 3-4 times a week while many (32\%) played every day. It was shown that students who 
played computer games for 2 to 3 hours a day scored higher on expressed anger than those who played for less than half an hour a day. Moreover, higher levels of anger were found in young people who preferred action, adventure, fight, and strategy games than in those who played other types of computer games.

\section{METHODOLOGY}

A validated instrument was distributed in Internet cafés in Guagua - one of the municipalities of Pampanga, Philippines. The construction of the questionnaire was guided by different studies (Plutchik, 1982; Larsen, 2007; Manstead, 2007; Sullivan, 2009). Guagua has a population of 111,199 (National Statistics Office, 2010) that served as the basis in computing the minimum sample size. A 100-minimum sample size was computed $(\mathrm{e}=0.10)$. One hundred survey forms were distributed evenly in the morning (between 7 a.m. to 11:59 a.m.), afternoon (between 1 p.m. to 6 p.m.), and evening (between 6:01 p.m. to 9 p.m.; the evening session exceeded one survey form). Respondents (regardless of age, sex, religious affiliation, etc.) answered the questionnaire, and all forms were retrieved.

The questionnaire was utilized to gather demographic data, gaming behaviors, and emotions exhibited by gamers in cyber cafés. The study employed a semantic differential in rating the emotions of the respondents. The statistical tools used in the treatment of data included frequency counts, percentages, mean, and Pearson correlation. Frequency counts, percentages, and mean were utilized to describe the data. Pearson correlation was used to determine the relationship of gaming behaviors and emotions exhibited of the respondents. $1 \%$ level of probability with $99 \%$ reliability was followed to determine the degree of significance of the findings.

\section{RESULTS AND DISCUSSION}

Most gamers were at least twenty years old $(f=68,68 \%)$ and were college students ( $f=64,64 \%$ ). The majority of the respondents were graduating students (as indicated by the average age), male ( $\mathrm{f}=91,91 \%$ ) and single ( $\mathrm{f}=96,96 \%$ ). It was also revealed that most of the respondents were not working (i.e., students) (Students, $f=48,48 \%$ ). It is interesting to note that the majority of the respondents had computer access at home ( $\mathrm{f}=$ 79, 79\%). However, Internet access was still a barrier (No Internet access at home, $f=81$, $81 \%$ ). The affordability of computers due to their decreasing cost enables a person to own a personal computer. However, this is not the case for Internet access. Internet access is 
still relatively expensive. A monthly Internet subscription fee of Php1,000 (US\$25) is not seen as a primary household commodity. Further, such a fee is relatively expensive for a family who belongs to the middle-class ( $f=99,99 \%$ ).

In terms of the gaming behaviors of the respondents, about 52\% ( $f=52$ ) visited cyber cafés at most four times a week while the remaining gamers visited cyber cafés at least five times a week ( $\mathrm{f}=48,48 \%$ ). This finding shows that there was an almost even distribution of gamers who visit cyber cafés on either an occasional or a frequent basis. While some gamers tended to limit their visits cyber cafés and to play games prudently, others exhibited a more recurrent visiting and gaming pattern. Clearly, the disparity could not be attributed to the profile of the respondents since the profile of the respondents was homogenous. It can be deduced that other factors could explain this phenomenon such as self-restraint, self-discipline, or the influence of other people (e.g., parents that monitor their children).

Gamers spent more than 2 hours (mean $=2.73$ hours) per visit playing games. This finding gives a clear indication of the gaming behavior of the respondents in terms of time expenditures. It is reasonable to infer from this data that the respondents to this study could prudently manage the amount of time they devote to playing games. In other words, they tended to visit cyber cafés frequently, but for relatively short durations per visit. Self-reported frequency of visit data confirmed this conclusion (mean $=4.06$, frequent). Gaming in cyber cafés was also done predominantly during the night ( $\mathrm{f}=61$, $61 \%$ ). This is not surprising since gamers had more time to play during the night when their classes were over than during the rest of the day when they had to attend school.

Gamers reported they were very happy (mean $=4.56$ ) when they were playing computer games. Excitement $($ mean $=4.22)$ and delight $($ mean $=4.33)$ were also dominant emotions. These positive emotions signify that gamers showed cheerful feelings when they were playing computers games. Interestingly, they also felt negative emotions while playing computer games. They felt anxiety (mean $=3.90$ ), irritation (mean $=4.00)$, and stress $($ mean $=4.15)$. On the other hand, they felt pressure to a lesser extent when they were competing with a better player. Stress was the most prominent negative emotion felt by computer gamers. These findings confirm the assumptions of the study that mixed emotions were shown while playing computer games.

This can be explained by the nature of the games they play. The top three most played games require gamers to dedicate time to establish game dominance in terms of power, game incentives, game character's life and strength, and watchtowers. From the 
gamers' perspective, these resources would be wasted if they were to be defeated in a game. Hence, maintaining game dominance becomes stressful.

The number of years spent playing computer games was significantly related to stress $(r=0.33, p<0.01)$ and anxiety $(r=0.36, p<0.01)$ (See Table 1.). The findings indicate that stress level and concerns about being defeated in a game build up when the number of years a gamer has spent playing games increases. As the player progresses to ever higher game levels, it becomes more difficult for the gamer to achieve the next higher level. Consequently, the competitive environment intensifies, inducing more stress on long-term gamers.

Meanwhile, frequency of gaming was also related to anxiety $(r=0.27, p<0.01)$. This can be explained by the gamer's need to play games constantly so that his game characters will be more dominant and powerful. Gamers need to invest effort, time, and money not only to achieve a remarkable game status but also to retain such status. Thus, a single mistake in game strategy may lead to defeat and loss of hard-earned resources. Awareness of these consequences results in gamer anxiety. It was observed that anxiety had a significant and positive relationship to two gaming behaviors (i.e., frequency of gaming and numbers of years spent playing games). This implies that, unlike stress which is primarily correlated with number of years spent playing games, anxiety was more sensitive to and more readily triggered by multiple gaming behaviors.

It is also interesting to note that emotions related to gaming behaviors were negative emotions. None of the positive emotions had a significant relationship to gaming behaviors. This implies the possibility that higher game engagement may lead to the gamers' expression or manifestation of negative emotions. Nonetheless, the study emphasized that these negative emotions were exhibited only during the game. The study did not establish that these emotions were carried over in the gamers' actual lives.

The findings of the study are of theoretical and practical importance. From the theoretical point of view, the findings provide empirical evidence that gamers could feel positive as well as negative emotions. It also confirms that emotions could be dependent on one another. This supports the emotion theory of Larsen (2007). From a practical standpoint, the findings offer powerful and cautionary reminders for parents, game developers, and gamers. Parents are advised to monitor their children's gaming behavior. Gamer developers are encouraged to design games that could detect gamers' excessive gaming behaviors. A recommender system that enables the game to be paused is a highly desired game design feature. Lastly, gamers themselves have to be cautious about their 
gaming behaviors and practice self-restraint. Hence, prudence and temperance are two virtues that gamers should learn to apply in these activities.

\begin{tabular}{|c|c|c|c|}
\hline \multirow[b]{2}{*}{ Emotions } & \multicolumn{3}{|c|}{ Gaming Behaviors $(n=100)$} \\
\hline & $\begin{array}{c}\text { Hours Spent per } \\
\text { Visit }\end{array}$ & $\begin{array}{c}\text { Frequency of } \\
\text { Gaming }\end{array}$ & $\begin{array}{l}\text { Length of Years } \\
\text { Playing Games }\end{array}$ \\
\hline Happiness & $r=0.16, p=0.101$ & $r=0.11, p=0.260$ & $r=0.04, p=0.708$ \\
\hline Stress & $r=0.05, p=0.596$ & $r=0.10, p=0.336$ & $r=0.33, p<0.01$ \\
\hline Excitement & $r=0.07, p=0.474$ & $r=0.19, p=0.06$ & $r=0.24, p=0.02$ \\
\hline Disappointment & $r=-0.02, p=0.857$ & $r=0.17, p=0.093$ & $r=0.05, p=0.641$ \\
\hline Irritation & $r=0.11, p=0.290$ & $r=0.07, p=0.476$ & $r=0.18, p=0.08$ \\
\hline Delight & $r=0.13, p=0.183$ & $r=0.02, p=0.838$ & $r=0.05, p=0.638$ \\
\hline Anxiety & $r=0.13, p=0.202$ & $r=0.27, p<0.01$ & $r=0.36, p<0.01$ \\
\hline Pressure & $r=-0.03, p=0.795$ & $r=0.01, p=0.951$ & $r=-0.01, p=0.919$ \\
\hline
\end{tabular}

However, there are still research gaps that need to be addressed. First, there are other emotions, such as anger, excitement, frustration, boredom, and amusement that were not included in the present study. Second, it is unclear what coping mechanisms gamers employ when they are confronted with game defeat. Lastly, it is worth investigating the players' gaming behaviors after a game defeat. An investigation into whether they continue the game or shift to another game and the explanation of such behavior would be of interest.

\section{CONCLUSIONS AND RECOMMENDATIONS}

Based on the findings presented, the null hypothesis stating that there is no significant relationship between emotions exhibited while playing computer games and the gaming behaviors of the respondents is partially rejected. Hence, not all gaming behaviors were related to the emotions exhibited while playing computer games. It also concluded that anxiety was a more sensitive emotion than stress. The study revealed that there were two types of gamers: prudent gamers who visited cyber cafés no more than twice a week and excessive gamers who visited three or more times weekly. 
The study also provided empirical evidence to support Larsen's (2007) emotion theory. It was shown that gamers exhibited independent and mixed emotions while playing computer games, and these emotions could be positive or negative. The study calls for further investigation of other emotions that were not captured in the study. Emotions such as anger, excitement, boredom, frustration, and amusement can be investigated. It is also not yet known what coping mechanisms gamers may use and what their associated behaviors are when they are defeated in a game. Further study may shed light on these questions.

\section{ACKNOWLEDGMENTS}

The authors are greatly indebted to Dr. Ester A. Garcia, Dr. Linda P. Santiago, Dr. Olivia C. Caoili, Dean Rodany A. Merida, and Dr. Socorro R. Villamejor. This paper is funded by the University of the East.

\section{REFERENCES}

Bringula, R., Bonifacio, J., Natanauan, A., Manuel, M., \& Panganiban, K. (2012). Pattern of internet usage in cyber cafés in Manila: An exploratory study. International Journal of Cyber Society and Education, 5(2), 151-164 http://dx.doi.org/10.7903/ijcse.1102.

Demirok, M., Ozdamli, F., Hursen, C., Ozcinar, Z., Kutguner, M., \& Uzunboylu, H. (2012). The relationship of computer games and reported anger in young people. Australian Journal of Guidance and Counselling, 22(1), 33-43. http://dx.doi.org/10.1017/jgc.2012.4.

Devilly, G.J., Callahan, P., \& Armitage, G. (2012). The effect of violent videogame playtime on anger. Australian Psychologist, 47(2), 98-107. http://dx.doi.org/10.1111/j.1742-9544.2010.00008.x.

Hussain, Z., \& Griffiths, M.D. (2009). The attitudes, feelings, and experiences of online gamers: A qualitative analysis. CyberPsychology \& Behavior, 12(6), 747-753. http://dx.doi.org/10.1089=cpb.2009.0059.

Larsen, R.J. (2007). Independence of positive and negative affect. In R.F. Baumeister and K. D. Vohs (Eds.), Encyclopedia of social psychology (pp. 468-470). Thousand Oaks, CA: SAGE Publications. http://dx.doi.org/10.4135/9781412956253.n278.

Manstead, A.S.R. (2007). Emotion. In R.F. Baumeister and K.D. Vohs (Eds.), Encyclopedia of social psychology (pp. 285-291). Thousand Oaks, CA: SAGE 
Publications. http://dx.doi.org/10.4135/9781412956253.n175.

National Statistics Office. (May, 2014). Total population by province, city, municipality and barangay: As of May 1, 2010. Retrieved from http://www.census.gov.ph/sites/default/files/attachments/hsd/pressrelease/Central\%2 OLuzon.pdf

Plutchik, R. (1982). A psychoevolutionary theory of emotions. Social Science Information, 21(4-5), 529-553. http://dx.doi.org/10.1177/053901882021004003.

Poels, K., Van Den Hoogen, W., Ijsselsteijn, W., \& De Kort, Y. (2012). Pleasure to play, arousal to stay: The effect of player emotions on digital game preferences and playing time. CyberPsychology, Behavior, and Social Networking, 15(1), 1-6. http://dx.doi.org/10.1089/cyber.2010.0040.

Sullivan, L.E., (2009). Cannon-bard theory. In L. Sullivan (Ed.), The SAGE glossary of the social and behavioral sciences (pp. 60-61). Thousand Oaks, CA: SAGE Reference.

Tsahuridu, E.E. (2009). Emotion. In C. Wankel (Ed.), Encyclopedia of business in today's world (pp. 587-589). Thousand Oaks, CA: SAGE Publications. http://dx.doi.org/10.4135/9781412964289.n339. 
